\title{
DESENVOLVIMENTO DE CULTIVARES DE MARACUJAZEIRO EM DIFERENTES SUBSTRATOS E DIMENSÕES DE RECIPIENTES
}

\author{
Henrique Guimarães de Favare ${ }^{1}$, Leonarda Grillo Neves ${ }^{1}$, Milson Evaldo Serafim ${ }^{2}$, Adriel \\ Fernandes Correa ${ }^{1}$, Marco Antônio Bareli ${ }^{1}$, Petterson Baptista da Luz ${ }^{1}$, Kelly Lana Araújo ${ }^{1}$ \\ ${ }^{1}$ Universidade do Estado de Mato Grosso - UNEMAT - Departamento de Agronomia. Av. São João, s/n, Bairro Cavalhada, CEP \\ 78200-000, Cáceres, MT, Brasil. E-mail: guimaraesfavare@gmail.com \\ ${ }^{2}$ Instituto Federal de Educação, Ciência e Tecnologia de Mato Grosso - Campus Cáceres .Av. dos Ramires, s/n, , Distrito \\ Industrial - CEP 78.106-960,Cáceres-MT. E-mail: milsonserafim@ gmail.com
}

\section{RESUMO}

A produtividade e longevidade da lavoura de maracujazeiro dependem da qualidade das mudas utilizadas. Objetivou-se nesse trabalho estudar o desenvolvimento de mudas de seis cultivares de maracujazeiro em dois volumes de recipientes de mesmo material e três composições de substrato. $\mathrm{O}$ experimento foi desenvolvido em um telado coberto, localizado na área da Universidade do Estado de Mato Grosso - UNEMAT, Campus de Cáceres, entre os meses de setembro e novembro de 2011. O delineamento experimental foi o de blocos casualizados com fatorial $2 \times 6 \times 3$, onde o primeiro fator foram o diferentes recipientes, o segundo fator foram as cultivares e o terceiro fator foram os substratos, com três repetições e quatro plantas por parcela, totalizando 432 plantas. As variáveis estudadas foram massa fresca e seca da parte aérea e da raiz, comprimento da raiz, número de folhas, e altura de planta. Os resultados foram submetidos à análise de variância e as médias comparadas pelo teste de Scott \& Knott ao nível de 5\% significância. As variedades IAC 277, Sol do Cerrado, FB 200 e Gigante Amarelo tiveram melhor desenvolvimento no substrato terra + esterco aviário, independente da dimensão do recipiente. Neste experimento, a combinação do menor recipiente com o esterco aviário é a alternativa mais viável para a produção de mudas de maracujazeiro amarelo no município de Cáceres-MT, Brasil.

Palavras-chave: Passiflora edulis, produção de mudas, interação genótipo ambiente

\section{DEVELOPMENT OF PASSION FRUIT CULTIVARS IN DIFFERENT SUBSTRATES AND DIMENSIONS OF CONTAINERS}

\section{ABSTRACT}

Productivity and longevity of the crop depends on the quality of passion fruit seedlings used. The objective of this work was to study the development of seedlings of six cultivars of passion fruits in two volumes of recipients of same material and three substrate compositions. The experiment was conducted in a greenhouse, located in the University of Mato Grosso UNEMAT, Caceres campus, Brazil, between the months at September and November 2011. The experimental design was a randomized block with factorial $2 \times 6 \times 3$, where the first factor was the different recipients, the second factor were the cultivars and the third factor were the substrates, with three replications with four plants per plot, totaling 432 plants. The variables studied were fresh and dry shoot and root, root length, leaf number and plant height. The results were submitted to ANOVA and means compared by the Scott \& Knott test at 5\% significance level. The IAC 277, Sol do Cerrado, FB 200 and Yellow Giant had their best development in 
poultry manure + soil substrate, regardless of the size of the container. In this experiment, the combination of smaller container with poultry manure is the most viable alternative for the production of yellow passion fruit seedlings in the city of Cáceres-MT, Brazil.

Key words: Passiflora edulis, seedling production, genotype environment interaction

\section{INTRODUÇÃO}

O Brasil é o principal produtor mundial de maracujá. A cultura é explorada, comercialmente, de norte a sul do território brasileiro, tanto nas regiões tropicais, quanto subtropicais, com condições que favorecem seu bom desenvolvimento. Seu cultivo encontra-se em fase de expansão, em razão das ótimas perspectivas de comercialização, principalmente devido aos bons preços alcançados no mercado de fruta fresca (Braga \& Junqueira, 2000; IBGE, 2011). Em 2010, a área plantada foi de 61.842 ha, com rendimento de produção superior 14,9 ton/ha (IBGE, 2013)

Para um crescimento consistente da passicultura no país é importante o uso de cultivares de elevado potencial e uniformidade de produção a campo, bem como o uso de mudas sadias e vigorosas. Considera-se que $60 \%$ do sucesso de uma cultura perene, como frutífera, estão na implantação de mudas de alta qualidade, associadas às práticas culturais adotadas (Minami et al., 1994).

Geralmente, fruteiras do tipo alógama são provindas de mudas oriundas de sementes. A semeadura em recipientes é a forma mais empregada na produção de mudas de maracujazeiro, pois apresenta como vantagem: maior precocidade, menor possibilidade de contaminação fitopatogênica, melhor controle ambiental, aproveitamento das sementes e da área de produção de mudas, e menor "stress" no transplante (Tessarioli Neto, 1995). O investimento em mudas é de suma importância na fruticultura, por ser um dos pré-requisitos ao sucesso de atividade (David et al., 1999).
Ao escolher um recipiente deve-se levar em consideração a facilidade de aquisição e manuseio. Para produção de mudas de plantas frutíferas, vários tipos e tamanhos de recipientes podem ser utilizados, sendo que os mais comuns são os sacos de polietileno preto (Ribeiro et al., 2005).

Dentre os fatores importantes para se obter mudas de qualidade, o substrato é um dos fatores de maior influência (Peixoto, 1986). Um bom substrato deve apresentar como características, fácil aquisição e transporte, ausência de patógenos, riqueza em nutrientes essenciais, textura, estrutura e pH adequado (Silva et al., 2001). Deve, ainda, possuir características físicas que assegurem quantidades adequadas de espaço poroso e retenção de água para melhor desenvolvimento da muda (Smiderle \& Minami, 2001).

As dimensões dos recipientes e os substratos utilizados são as primeiras informações a serem estudadas, para garantir a produção de mudas de alta qualidade (Jesus et al., 1987). Diante do exposto, este trabalho foi realizado com o objetivo de estudar o desenvolvimento de mudas de seis cultivares de maracujazeiro em recipientes com dois volumes distintos e três substratos.

\section{MATERIAL E MÉTODOS}

um telado coberto localizado na Universidade do Estado de Mato Grosso UNEMAT, campus de Cáceres, cujas coordenadas médias são latitude $16^{\circ} 4$ '35" S, longitude $57^{\circ} 39^{\prime} 11^{\prime \prime} \mathrm{W}$, altitude de $118 \mathrm{~m}$. A região apresenta clima tropical com estação seca (classificação climática de 
Köppen-Geiger: Aw), com média de temperatura anual de $26^{\circ} \mathrm{C}$ e pluviosidade de $1.335 \mathrm{~mm}$ ao ano. A temperatura mais alta ocorre no mês de outubro $\left(28^{\circ} \mathrm{C}\right)$ e a mais baixa nos meses de junho e julho (23 e $23^{\circ} \mathrm{C}$ ), podendo ocorrer temperaturas de até $40^{\circ} \mathrm{C}$ (Neves, 2011).

O experimento foi realizado no período de setembro a novembro de 2011 e as seis variedades de maracujazeiro amarelo estudadas foram: IAC 275, IAC 277, Sol do Cerrado, Ouro vermelho, FB 200, e Gigante Amarelo. Os dois recipientes foram saquinhos de polietileno com as dimensões de 22 x 5,5 cm (recipiente grande) e 14,5 x $3,5 \mathrm{~cm}$ (recipiente pequeno).

Os substratos utilizados foram: substrato comercial (Plantmax), terra de barranco + esterco aviário (2:1), terra de barranco + NPK $\left(2 \mathrm{Kg} / \mathrm{m}^{3}\right.$ de uréia, 10 $\mathrm{Kg} / \mathrm{m}^{3}$ de super fosfato simples e $8 \mathrm{Kg} / \mathrm{m}^{3}$ de $\mathrm{KCl}$ ). Nos dois últimos substratos foi adicionado calcário dolomítico na proporção de $10 \mathrm{Kg} / \mathrm{m}^{3}$, e após enchimento dos saquinhos foi feita irrigação para reação dos adubos e do calcário no solo, por um período 15 dias. A análise química dos substratos foi feita apenas nos substratos terra de barranco+esterco aviário e terra de barranco + NPK, e o substrato comercial segue a caracterização nutricional da embalagem do produto (Tabela 1).

Foram semeadas duas sementes por saquinho, e efetuado o raleio 20 dias após germinação.

$\mathrm{O}$ delineamento experimental foi de blocos casualizados com fatorial $2 \times 6 \times 3$, onde o primeiro fator representou os diferentes recipientes, o segundo fator as cultivares e o terceiro fator os substratos, com três repetições e quatro plantas por parcela, totalizando 432 plantas no experimento.

A avaliação final do experimento foi realizada 60 dias após emergência, sendo determinada a massa fresca e seca da parte aérea e da raiz, comprimento da raiz, número de folhas, e altura de planta.

Tabela 1. Análise química dos substratos terra de barranco + esterco aviário, terra de barranco + NPK e composição química do Plantmax.

\begin{tabular}{|c|c|c|c|c|c|c|c|c|c|c|c|c|c|}
\hline Substrato & $\mathrm{pH} \mathrm{H}_{2} \mathrm{O}$ & $\begin{array}{c}\mathrm{P} \\
\mathrm{mg} / \mathrm{dm}^{3}\end{array}$ & $\begin{array}{c}\mathrm{K} \\
--\end{array}$ & $\mathrm{Ca}$ & $\begin{array}{l}\mathrm{Mg} \\
\mathrm{C}\end{array}$ & $\begin{array}{c}\mathrm{Al} \\
\mathrm{molc} / \mathrm{d}\end{array}$ & $\mathrm{H}+\mathrm{Al}$ & SB & $\begin{array}{c}\text { M.O. } \\
\%\end{array}$ & CTC pH 7,0 & CTC ef. & $\begin{array}{l}\mathrm{V} \\
\%\end{array}$ & $\mathrm{~m}$ \\
\hline $\begin{array}{c}\text { Terra+ } \\
\text { Cama de frango }\end{array}$ & 6,7 & 23,1 & 0,2 & 1,2 & 0,4 & - & 1,2 & 1,8 & 0,9 & 3 & 1,8 & 60,6 & - \\
\hline Terra+ NPK & 6,2 & 34,6 & 0,3 & 1,3 & 0,3 & - & 4 & 1,9 & 1 & 6 & 1,9 & 32,1 & - \\
\hline & \multicolumn{13}{|c|}{ Composição } \\
\hline \multirow[t]{3}{*}{ Plantmax } & $\mathrm{N}$ & $\mathrm{P}$ & $\mathrm{K}$ & $\mathrm{Ca}$ & $\mathrm{Mg}$ & $S$ & B & $\mathrm{Fe}$ & $\mathrm{Cu}$ & $\mathrm{Mn}$ & $\mathrm{Zn}$ & & \\
\hline & \multicolumn{13}{|c|}{-----------------'mg Kg-1 } \\
\hline & 5,81 & 0,95 & 4,35 & 14,14 & 1,68 & 0,31 & 27,80 & 19826,0 & 0,01 & 225,0 & 76,40 & & \\
\hline
\end{tabular}


Para determinação da altura e comprimento da raiz, foi utilizada uma régua graduada em centímetros. O comprimento da raiz foi realizado medindo-se do colo às suas respectivas extremidades. $\mathrm{O}$ peso da massa fresca foi obtido pesando-se separadamente a parte aérea e o sistema radicular. Para a determinação da massa seca as amostras foram secas em estufa de circulação de ar forçado com temperatura de $65^{\circ} \mathrm{C}$, até atingir peso constante. Os resultados foram submetidos à análise de variância e as médias comparadas pelo teste de Scott \& Knott ao nível de 5\% de significância, utilizando-se o programa computacional Genes (Cruz, 2012).

\section{RESULTADOS E DISCUSSÃO}

Foi observada interação significativa entre as variedades e os recipientes somente para a variável altura de planta. As alturas das plantas das cultivares IAC 277, Sol do Cerrado, FB 200 e Gigante Amarelo foram significativamente maiores em relação às cultivares IAC 275 e Ouro Vermelho quando cultivadas em recipiente pequeno (Tabela 2 ).

A semelhança no desempenho das cultivares IAC 277, Sol do Cerrado, FB 200 e Gigante Amarelo foi um indicativo de que essas variedades de maracujá amarelo são adaptadas à região de Cáceres. Já as variedades IAC 275 e Ouro Vermelho não tiveram boa adaptação.

Não existiu diferença significativa no uso de saco de plástico grande e pequeno para produzir mudas de maracujazeiro amarelo, nas condições do experimento. Resultados contrários foram observando por Chagas (2006), no qual o número de folhas variou em função do tamanho do recipiente, onde as mudas produzidas nos recipientes grandes apresentaram $34 \%$ a mais de folhas em relação ao que foi obtido nos recipientes pequenos.

Resultados semelhantes ao deste trabalho foram observados por Silva et al.
(2010), que afirmaram que o tamanho dos recipientes não influenciou significativamente no desenvolvimento das plantas de maracujá amarelo.

Os sacos de polietileno permitem a obtenção de mudas vigorosas e de qualidade adequada para o plantio, embora tenham como desvantagens o aumento da área requerida de viveiro e a elevação do custo de produção, de transporte e plantio da muda (Melo, 1999). Neste sentido o saco de polietileno pequeno tem vantagem sobre o grande, pois utiliza menor quantidade de substrato.

Houve interação significativa entre as variedades e os substratos, indicado pela altura, massa fresca da parte aérea e da raiz e número de folhas. Quando feito o desdobramento pode-se perceber que o substrato terra + esterco de aviário proporcionou maior desempenho das cultivares de maracujá, observado em quase todas as variáveis analisadas, exceto quanto a massa seca da parte aérea e comprimento da raiz (Tabela 3).

O melhor desempenho das mudas no substrato terra + esterco de aviário, deve-se aos atributos físicos e químicos do esterco aviário, pois este possui altas concentrações de nutrientes propiciando o bom desenvolvimento das plantas, verificado ao fim do experimento, além de conter elevado percentual de material "inerte" de maravalha e, ou casca de arroz.

Mendonça et al. (2003) num experimento comparando diferentes substratos e recipientes na formação de mudas de mamoeiro 'Sunrise solo' (Carica papaya L.), obtiveram resultados contrários ao deste trabalho, pois constataram que o substrato Plantmax, associado ao recipiente saco de polietileno, favoreceram $o$ crescimento das mudas, número de folhas, matéria fresca e seca da parte aérea e raiz. 
Tabela 2. Valores médios de altura das mudas de diferentes variedades de maracujá amarelo obtidas em diferentes recipientes, Cáceres-MT, 2012.

\begin{tabular}{|c|c|c|c|c|c|c|c|c|}
\hline \multirow[t]{2}{*}{ Variáveis } & \multicolumn{2}{|c|}{ Altura } & \multicolumn{2}{|c|}{ Massa Fresca Parte Aérea } & \multicolumn{2}{|c|}{ Massa Seca Parte Aérea } & \multicolumn{2}{|c|}{ Massa Fresca Raiz } \\
\hline & \multicolumn{8}{|c|}{ Recipientes } \\
\hline Cultivares & Grande & Pequeno & Grande & Pequeno & Grande & Pequeno & Grande & Pequeno \\
\hline IAC 275 & $11.9537 \mathrm{Aa}$ & $11.8297 \mathrm{Ab}$ & $5.5052 \mathrm{Aa}$ & $3.8357 \mathrm{Aa}$ & 2.6539 Aa & $0.8402 \mathrm{Aa}$ & $1.4627 \mathrm{Aa}$ & $0.7703 \mathrm{Aa}$ \\
\hline IAC 277 & $19.0370 \mathrm{Aa}$ & $22.3842 \mathrm{Aa}$ & $10.5962 \mathrm{Aa}$ & $9.8133 \mathrm{Aa}$ & $2.1108 \mathrm{Aa}$ & $1.8966 \mathrm{Aa}$ & $1.7312 \mathrm{Aa}$ & $1.3511 \mathrm{Aa}$ \\
\hline Sol do Cerrado & $16.8167 \mathrm{Aa}$ & $28.5750 \mathrm{Aa}$ & $8.5668 \mathrm{Aa}$ & 15.5178 Aa & $1.1350 \mathrm{Aa}$ & $3.1356 \mathrm{Aa}$ & $1.2681 \mathrm{Aa}$ & $1.2959 \mathrm{Aa}$ \\
\hline Ouro Vermelho & $16.6528 \mathrm{Aa}$ & $6.3639 \mathrm{Ab}$ & $10.0762 \mathrm{Aa}$ & $10.4600 \mathrm{Aa}$ & $1.9948 \mathrm{Aa}$ & $2.8666 \mathrm{Aa}$ & $1.4864 \mathrm{Aa}$ & $1.2017 \mathrm{Aa}$ \\
\hline FB 200 & $11.8519 \mathrm{Aa}$ & $21.6922 \mathrm{Aa}$ & $7.6086 \mathrm{Aa}$ & $9.9371 \mathrm{Aa}$ & $0.8684 \mathrm{Aa}$ & $2.1349 \mathrm{Aa}$ & $1.3346 \mathrm{Aa}$ & $2.0276 \mathrm{Aa}$ \\
\hline Gigante Amarelo & $6.7500 \mathrm{Aa}$ & $18.1444 \mathrm{Aa}$ & $2.5342 \mathrm{Aa}$ & $8.1203 \mathrm{Aa}$ & $0.4743 \mathrm{Aa}$ & $1.5797 \mathrm{Aa}$ & $1.1257 \mathrm{Aa}$ & $1.1608 \mathrm{Aa}$ \\
\hline
\end{tabular}

\begin{tabular}{|c|c|c|c|c|c|c|}
\hline \multirow{3}{*}{$\begin{array}{l}\text { Variáveis } \\
\text { Cultivares }\end{array}$} & \multicolumn{2}{|c|}{ Massa Seca Raiz } & \multicolumn{2}{|c|}{ Número Folhas } & \multicolumn{2}{|c|}{ Comprimento Raiz } \\
\hline & \multicolumn{6}{|c|}{ Recipientes } \\
\hline & Grande & Pequeno & Grande & Pequeno & Grande & Pequeno \\
\hline IAC 275 & $0.4823 \mathrm{Aa}$ & $0.2999 \mathrm{Aa}$ & $7.0833 \mathrm{Aa}$ & $5.4074 \mathrm{Aa}$ & 21.3056Aa & $17.8744 \mathrm{Aa}$ \\
\hline IAC 277 & $0.8779 \mathrm{Aa}$ & $0.4929 \mathrm{Aa}$ & $8.4352 \mathrm{Aa}$ & $9.3703 \mathrm{Aa}$ & 23.8861Aa & $24.8333 \mathrm{Aa}$ \\
\hline Sol do Cerrado & $0.4253 \mathrm{Aa}$ & $0.4782 \mathrm{Aa}$ & $7.7500 \mathrm{Aa}$ & $12.0556 \mathrm{Aa}$ & $23.0333 \mathrm{Aa}$ & $23.1019 \mathrm{Aa}$ \\
\hline Ouro Vermelho & $0.4693 \mathrm{Aa}$ & $0.5810 \mathrm{Aa}$ & $8.3056 \mathrm{Aa}$ & $9.6574 \mathrm{Aa}$ & 19.1389Aa & $17.6852 \mathrm{Aa}$ \\
\hline FB 200 & $0.3992 \mathrm{Aa}$ & $0.6740 \mathrm{Aa}$ & $6.6852 \mathrm{Aa}$ & $9.3056 \mathrm{Aa}$ & $20.3991 \mathrm{Aa}$ & $20.6944 \mathrm{Aa}$ \\
\hline Gigante Amarelo & $0.4013 \mathrm{Aa}$ & $0.4473 \mathrm{Aa}$ & $4.7778 \mathrm{Aa}$ & $91389 \mathrm{Aa}$ & $16.3667 \mathrm{Aa}$ & $24.0787 \mathrm{Aa}$ \\
\hline
\end{tabular}

*Médias seguidas pelas mesmas letras maiúsculas na horizontal constituem grupo estatisticamente homogêneo.

*Médias seguidas pelas mesmas letras minúsculas na vertical constituem grupo estatisticamente homogêneo.

*Teste de Scott \& Knott ao nível de 5\% significância. 
Tabela 3. Valores médios de altura, massa fresca parte aérea, massa seca da parte aérea massa fresca da raiz, massa seca da raiz numero de folhas e comprimento da raiz das mudas de diferentes variedades de maracujá amarelo obtidas em diferentes substratos, Cáceres-MT, 2012.

*Médias seguidas pelas mesmas letras maiúsculas na horizontal constituem grupo estatisticamente homogêneo.

\begin{tabular}{|c|c|c|c|c|c|c|c|c|c|}
\hline & & Terra+Esterco & Terra+NPK & Plantimax & Tra & amento & Terra+Esterco & Terra+NPK & Plantimax \\
\hline \multirow{6}{*}{ Altura } & IAC 275 & $26,6680 \mathrm{Ab}$ & $1,7500 \mathrm{Ba}$ & $7,2570 \mathrm{Ba}$ & \multirow{6}{*}{$\begin{array}{r}\text { Massa } \\
\text { seca da } \\
\text { raiz }\end{array}$} & IAC 275 & $1,0893 \mathrm{Aa}$ & $0,0350 \mathrm{Ba}$ & $0,0490 \mathrm{Ba}$ \\
\hline & IAC 277 & 44,3193 Аа & $9,1250 \mathrm{Ba}$ & $8,6875 \mathrm{Ba}$ & & IAC 277 & $1,6077 \mathrm{Aa}$ & $0,3458 \mathrm{Ba}$ & $0,1027 \mathrm{Ba}$ \\
\hline & Sol do Cerrado & $54,8750 \mathrm{Aa}$ & $2,6667 \mathrm{Ba}$ & $10,5458 \mathrm{Ba}$ & & Sol do Cerrado & $1,1952 \mathrm{Aa}$ & $0,0483 \mathrm{Ba}$ & $0,1118 \mathrm{Ba}$ \\
\hline & Ouro Vermelho & $26,6750 \mathrm{Ab}$ & $0,0000 \mathrm{Ba}$ & 7,8500 Ba & & Ouro Vermelho & $1,4902 \mathrm{Aa}$ & $0,0000 \mathrm{Ba}$ & $0,0853 \mathrm{Ba}$ \\
\hline & FB 200 & $32,3987 \mathrm{Ab}$ & $4,7500 \mathrm{Ba}$ & $13,1675 \mathrm{Ba}$ & & FB 200 & $1,2713 \mathrm{Aa}$ & $0,1317 \mathrm{Ba}$ & $0,2068 \mathrm{Ba}$ \\
\hline & Gigante Amarelo & $26,4375 \mathrm{Ab}$ & $4,2500 \mathrm{Ba}$ & $6,6542 \mathrm{Ba}$ & & Gigante Amarelo & 1,0893 Aa & $0,0917 \mathrm{Ba}$ & $0,0920 \mathrm{Ba}$ \\
\hline \multirow{6}{*}{$\begin{array}{l}\text { Massa } \\
\text { fresca } \\
\text { parte } \\
\text { aérea }\end{array}$} & IAC 275 & $12,9862 \mathrm{Ab}$ & $0,4917 \mathrm{Ba}$ & $0,5335 \mathrm{Ba}$ & \multirow{6}{*}{$\begin{array}{l}\text { Número } \\
\text { de folhas }\end{array}$} & IAC 275 & $11,1388 \mathrm{Ab}$ & $2,1667 \mathrm{Ba}$ & $5,4307 \mathrm{Ba}$ \\
\hline & IAC 277 & $24,6272 \mathrm{Aa}$ & $4,0425 \mathrm{Ba}$ & $1,9447 \mathrm{Ba}$ & & IAC 277 & $15,3750 \mathrm{Ab}$ & $5,5000 \mathrm{Ba}$ & $5,8333 \mathrm{Ba}$ \\
\hline & Sol do Cerrado & $33,9563 \mathrm{Aa}$ & $0,1950 \mathrm{Ba}$ & $1,9755 \mathrm{Ba}$ & & Sol do Cerrado & $20,0000 \mathrm{Aa}$ & $2,3333 \mathrm{Ba}$ & 7,3750 Ba \\
\hline & Ouro Vermelho & $29,8848 \mathrm{Aa}$ & $0,0000 \mathrm{Ba}$ & $0,9195 \mathrm{Ba}$ & & Ouro Vermelho & $20,2362 \mathrm{Aa}$ & $0,0000 \mathrm{Ca}$ & $6,7083 \mathrm{Ba}$ \\
\hline & FB 200 & $19,0912 \mathrm{Ab}$ & $1,4300 \mathrm{Ba}$ & $5,7973 \mathrm{Ba}$ & & FB 200 & $12,4028 \mathrm{Ab}$ & $3,5000 \mathrm{Ba}$ & 8,0833 Aa \\
\hline & Gigante Amarelo & $14,2127 \mathrm{Ab}$ & $1,1450 \mathrm{Ba}$ & $0,6242 \mathrm{Ba}$ & & Gigante Amarelo & $11,7500 \mathrm{Ab}$ & $2,8333 \mathrm{Ba}$ & $6,2917 \mathrm{Ba}$ \\
\hline \multirow{6}{*}{$\begin{array}{l}\text { Massa } \\
\text { seca } \\
\text { parte } \\
\text { aeréa }\end{array}$} & IAC 275 & $5,0210 \mathrm{Aa}$ & $0,1150 \mathrm{Ba}$ & $0,1052 \mathrm{Ba}$ & \multirow{6}{*}{$\begin{array}{r}\text { Comp. da } \\
\text { raiz }\end{array}$} & IAC 275 & $28,1380 \mathrm{Aa}$ & $4,5000 \mathrm{Ba}$ & $26,1320 \mathrm{Aa}$ \\
\hline & IAC 277 & $4,7038 \mathrm{Aa}$ & $0,9383 \mathrm{Ba}$ & $0,3688 \mathrm{Ba}$ & & IAC 277 & $34,3333 \mathrm{Aa}$ & $17,0583 \mathrm{Ba}$ & $21,6875 \mathrm{Ba}$ \\
\hline & Sol do Cerrado & $5,9875 \mathrm{Aa}$ & $0,0667 \mathrm{Ba}$ & $0,3517 \mathrm{Ba}$ & & Sol do Cerrado & $32,5987 \mathrm{Aa}$ & $5,5833 \mathrm{Ba}$ & $31,0208 \mathrm{Aa}$ \\
\hline & Ouro Vermelho & $7,1108 \mathrm{Aa}$ & $0,0000 \mathrm{Ba}$ & $0,1812 \mathrm{Ba}$ & & Ouro Vermelho & 31,4862 Aa & $0,0000 \mathrm{Ba}$ & $23,7500 \mathrm{Aa}$ \\
\hline & FB 200 & $3,0940 \mathrm{Aa}$ & $0,3550 \mathrm{Aa}$ & $1,0660 \mathrm{Aa}$ & & FB 200 & $30,5695 \mathrm{Aa}$ & $5,4167 \mathrm{Ba}$ & $25,6542 \mathrm{Aa}$ \\
\hline & Gigante Amarelo & $2,7082 \mathrm{Aa}$ & $0,2600 \mathrm{Aa}$ & $0,1128 \mathrm{Aa}$ & & Gigante Amarelo & $28.8958 \mathrm{Aa}$ & 7,3333 Ba & $24,4388 \mathrm{Aa}$ \\
\hline \multirow{6}{*}{$\begin{array}{l}\text { Massa } \\
\text { fresca } \\
\text { da } \\
\text { raiz }\end{array}$} & IAC 275 & $3,1673 \mathrm{Aa}$ & $0,0367 \mathrm{Ba}$ & $0,1455 \mathrm{Ba}$ & & & & & \\
\hline & IAC 277 & $3,7038 \mathrm{Aa}$ & $0,5983 \mathrm{Ba}$ & $0,3213 \mathrm{Ba}$ & & & & & \\
\hline & Sol do Cerrado & $3,4375 \mathrm{Aa}$ & $0,1100 \mathrm{Ba}$ & $0,2985 \mathrm{Ba}$ & & & & & \\
\hline & Ouro Vermelho & $3,8407 \mathrm{Aa}$ & $0,0000 \mathrm{Ba}$ & $0,1915 \mathrm{Ba}$ & & & & & \\
\hline & FB 200 & $4,1310 \mathrm{Aa}$ & $0,2800 \mathrm{Ba}$ & $0,6322 \mathrm{Ba}$ & & & & & \\
\hline & Gigante Amarelo & $2,9493 \mathrm{Aa}$ & $0,1917 \mathrm{Ba}$ & $0,2887 \mathrm{Ba}$ & & & & & \\
\hline
\end{tabular}

*Médias seguidas pelas mesmas letras minúsculas na vertical constituem grupo estatisticamente homogêneo.

*Teste de Scott \& Knott ao nível de 5\% significância. 
Rodrigues (2004), em pesquisa utilizando esterco de aviário para produção de hortaliças em sistema orgânico, afirmou que o substrato industrial Plantmax não é capaz de suprir as necessidades nutricionais do pimentão, representando primordialmente um suporte físico adequado à emergência das plântulas. Portanto, no caso do uso desse substrato, seria necessária suplementação mineral a fim de conduzir as plântulas até a fase de transplantio.

\section{CONCLUSÃO}

As variedades IAC 277 e Sol do Cerrado apresentaram melhor desenvolvimento no substrato terra de barranco com esterco aviário, independente da dimensão do recipiente.

$\mathrm{O}$ recipiente pequeno pode ser utilizado na produção de mudas das variedades de maracujazeiro amarelo, por proporcionar economia de substrato.

\section{REFERÊNCIAS BIBLIOGRÁFICAS}

BRAGA, M. F.; JUNQUEIRA, N. T. V. 2000. Uso potencial de outras espécies do gênero Passiflora. Informe Agropecuário, Belo Horizonte, v. 1, n. 206, p. 72-75.

CHAGAS, I. M.; TAVARES, J. C.; FREITAS, R. S.; RODRIGUES, G. S. O. 2006. Formação de mudas de maracujá amarelo em quatro tamanhos de recipiente. Revista Verde, Mossoró, v.1, n.2, p. 122-133 julho/dezembro.

CRUZ, C. D. 2012. Programa Genes: versão Windows; aplicativo computacional em genética e estatística. Viçosa: UFV, 648 p. (versão 2012).

DAVID, D. V.; SILVA, J. M. A.; SILVA, P. M. 1999. Diagnóstico de produção e comercialização de mudas e semente de espécies frutíferas na região Nordeste do Brasil. Viçosa, MG: FUNABE; UFV, $215 \mathrm{p}$.
DAVID, M. A.; MENDONÇA, V.; REIS, L. L. 2008. Efeito de doses de superfosfato simples e de matéria orgânica sobre o crescimento de mudas de maracujazeiro amarelo. Pesquisa Agropecuária Tropical, Goiânia, v. 38, n. 3, p. 147-152, julho/setembro.

IBGE. 2013. Instituto brasileiro de geografia e estatística. Séries Estatísticas \& Séries Históricas. Disponível em: < http://www.ibge.gov.br > Acesso em: 15 de março de 2013.

JESUS, R. M.; MENANDRO, M. S.; BATISTA, J. L. F.; COUTO, H. T. Z. 1987. Efeito do tamanho do recipiente, tipo de substrato e sombreamento na produção de mudas de louro (Cordia trichotoma (Vell.) Arrab.) e gonçalo-alves (Astronium fraxinifolium Schott). Instituto de Pesquisas e Estudos Florestais, Piracicaba, n.37, p.13-19, dez.

MELO, B. 1999. Estudos sobre produção de mudas de cafeeiro (Coffea arabica L.) em tubetes. 1999. 119 p. Tese (Doutorado em Fitotecnia) - Universidade Federal de Lavras, Lavras.

MENDONÇA, V.; ARAÚJO NETO, S. E.; RAMOS, J. D.; PIO, P.; GONTIJO, T. C. A. 2003. Diferentes substratos e recipientes na formação de mudas de mamoeiro 'Sunrise Solo'. Revista Brasileira de Fruticultura, Jaboticabal, v. 25, n. 1, p. 127-130.

MINAMI, K.; TESSARIOLI NETO, J.; PENTEADO, S.R.; ESCARPARI FILHO, J.A. 1994. Produção de mudas hortícolas de alta qualidade. Piracicaba: ESALQ/SEBRAE, $155 \mathrm{p}$.

NEVES, S. M. A. S.; NUNES, M C. M.; NEVES, R. J. 2011. Caracterização das condições climáticas de Cáceres/MT Brasil, no período de 1971 a 2009: subsídio às atividades agropecuárias e turísticas municipais. Boletim Goiano de Geografia, Goiânia, v. 31, n. 2, p. 55-68, jul./dez. 
PEIXOTO, J. R. 1986. Efeito da matéria orgânica, do superfosfato simples e do cloreto de potássio na formação de mudas de maracujazeiro azedo (Passiflora edulis f. flavicarpa Deneger). 1986. 101 p. Dissertação (Mestrado em Agronomia) - Escola Superior de Agricultura, Lavras,

RIBEIRO, M. C.C.; MORAIS, M.J.A. DE; SOUSA, A.H.; LINHARES, P.C.F.; BARROS JÚNIOR, A.P. 2005. Produção de mudas de maracujá-amarelo com diferentes substratos e recipientes. Caatinga, Mossoró, v.18, n.3, p.155-158, julho/setembro.

RODRIGUES, J. R. Caracterização e avaliação de compostos à base de capim 'napier' (Pennisetum purpureum Schumach) e esterco de "cama" de aviário para produção de hortaliças em sistema orgânico. 2004. 105 p. Dissertação (Mestrado em Fitotecnia) Universidade Federal Rural do Rio de Janeiro, Seropédica.

SILVA, E. A.; MARUYAMA, W. I.; MENDONÇA, V.; FRANCISCO, M. G. S.; BARDIVIESSO, D. M.; TOSTA, M. S. 2010. Composição de substratos e tamanho de recipientes na produção e qualidade das mudas de maracujazeiro amarelo. Ciências e agrotecnologia, Lavras, v. 34, n. 3, p. 588-595, maio/jun.

SILVA, R. P.; PEIXOTO, J. R.; JUNQUEIRA, N. T. V. 2001. Influência de diversos substratos no desenvolvimento de mudas de maracujazeiro azedo (Passiflora edulis Sims f. flavicarpa Deg). Revista Brasileira de Fruticultura, Jaboticabal, v.23, n.2, p. 377-381, ago.

SOUZA, M. 1983. Nutrição e adubação para produzir mudas frutíferas. Informe Agropecuário, Belo Horizonte, v.9, n.102, p. 40-43.

SMIDERLE, O. S.; MINAMI, K. 2001. Emergência e vigor de plântulas de goiabeira em diferentes substratos.
Revista Científica Rural, Bagé, v.6, n.1, p.38-45,

TESSARIOLI NETO, J. 1995. Recipientes, embalagens e acondicionamentos de mudas de hortaliças. In: MINAMI, K. Produção de mudas de alta qualidade em horticultura. São Paulo: T.A. Queiroz, cap.4, p. 59-64. 